\title{
A qualitative study exploring the impact and consequence of the medicines use review service on pharmacy support-staff
}

\author{
Asam LATIF, Helen F. BOARDMAN, Kristian POLLOCK
} Received (first version): 24-Mar-2013 Accepted: 21-Jun-2013

\begin{abstract}
*
Background: Pharmacy support-staff (pharmacy technicians, dispensers and Medicines Counter Assistants) support the delivery of pharmaceutical and retail functions of the pharmacy. Workflow is supervised and at times dependent upon the pharmacist's presence. Policy makers and pharmacy's representative bodies are seeking to extend the community pharmacist's role including requiring the pharmacist to undertake private consultations away from the dispensary and shop floor areas. However, support-staff voices are seldom heard and little is known about the impact such policies have on them.

Objective: The objective of this study is to explore the impact and consequences of the English Medicine Use Review (MUR) service on pharmacy support-staff.
\end{abstract}

Method: Ten weeks of ethnographic-oriented observations in two English community pharmacies and interviews with 5 pharmacists and 12 supportstaff. A thematic approach was used to analyse the data.

Results: Despite viewing MURs as a worthwhile activity, interviews with support-staff revealed that some felt frustrated when they were left to explain to patients why the pharmacist was not available when carrying out an MUR. Dependency on the pharmacist to complete professional and accuracy checks on prescriptions grieved dispensing staff because dispensing workflow was disrupted and they could not get their work done. Medicines Counter Assistants were observed to have less dependency when selling medicines but some still reported concerns over of customers and patients waiting for the pharmacist. A range of tacit and ad hoc strategies were consequently found to be deployed to handle situations when the pharmacist was absent performing an MUR.

Conclusions: Consideration should be given to support-staff and pharmacists' existing work obligations when developing new pharmacy extended roles that require private consultations with patients. Understanding organisational culture and providing adequate resourcing for new services

\footnotetext{
*Asam LATIF. PhD. Division of Social Research in Medicines and Health, School of Pharmacy, University of Nottingham. Nottingham (United Kingdom).

Helen F. BOARDMAN. PhD. Division of Social Research in Medicines and Health, School of Pharmacy, University of Nottingham. Nottingham (United Kingdom).

Kristian POLLOCK. PhD. School of Nursing, Midwifery, and Physiotherapy. University of Nottingham. Nottingham (United Kingdom).
}

are needed to avoid improvisations or enactments by pharmacy support-staff and to allow successful innovation and policy implementation.

Keywords: Pharmacists' Aides; Pharmacists; Workflow; Community Pharmacy Services; Drug Utilization Review; Professional Practice; United Kingdom

\section{ESTUDIO CUALITATIVO EXPLORANDO EL IMPACTO Y LAS CONSECUENCIAS DEL SERVICIO DE REVISIÓN DE USO DE MEDICAMENTO SOBRE EL PERSONAL DE APOYO EN LA FARMACIA}

RESUMEN

Antecedentes: El personal de apoyo en la farmacia (auxiliares de farmacia, dispensadores, y ayudantes de mostrador) ayuda en la entrega de medicamentos y las funciones de venta en la farmacia. El flujo de trabajo esta supervisado y a veces es dependiente de la presencia del farmacéutico. Los políticos y los cuerpos de representación de los farmacéuticos buscan extender el papel del farmacéutico comunitario, incluyendo exigir al farmacéutico que realice consultas privadas fuera de la zona de dispensación y de las partes del público. Sin embargo, rara vez se oyen las voces del personal de apoyo y se sabe poco del impacto de estas políticas sobre ellos.

Objetivo: El objetivo de este estudio es explorar el impacto y las consecuencias del servicio ingles de revisión del uso de medicamentos (MUR) sobre el personal de apoyo en la farmacia.

Métodos: Diez semanas de observaciones de tipo etnográfico en dos farmacias comunitarias inglesas y entrevistas con 5 farmacéuticos y 12 personas de apoyo. Se utilizó un abordaje temático para analizar los datos.

Resultados: A pesar de ver las MUR como una actividad que valiosa, las entrevistas con el personal de apoyo reveló que se sienten frustrados cuando se les dejó y tuvieron que explicar a los pacientes porque el farmacéutico no estaba disponible cuando estaba realizando una MUR. La dependencia del farmacéutico para completar las comprobaciones profesionales y la idoneidad de las prescripciones incomodaba al personal dispensador porque el flujo de trabajo de la dispensación tenía que interrumpirse y no podían hacer el trabajo solos. Se observó que los ayudantes de mostrador tenían menos dependencia cuando vendían medicamentos, pero algunos reportaron preocupaciones sobre los clientes y pacientes 
cuando esperaban por el farmacéutico. Se encontró un abanico de estrategias tácitas y ad-hoc que se desarrollaron para manejar las situaciones en las que el farmacéutico estaba ausente realizando una MUR.

Conclusiones: Se debería tener en cuenta las obligaciones del trabajo actual del personal de apoyo y del farmacéutico cuando se desarrollan nuevos papeles ampliados en la farmacia, que requieran consultas privadas con pacientes. Se necesita comprender la cultura organizaciones y realojar adecuadamente los recursos para los nuevos servicios para evitar improvisaciones o actuaciones del personal de apoyo en la farmacia y para permitir innovación y la implementación de políticas con éxito.

Palabras clave: Auxiliares de Farmacia; Farmacéuticos; Flujo de Trabajo; Servicios de Farmacia Comunitaria; Revisión de la Utilización de Medicamentos; Professional Practice; Reino Unido

\section{INTRODUCTION}

Within UK community pharmacies, the delivery of pharmaceutical services and retail functions of the pharmacy are typically carried out by three groups of pharmacy support-staff (Medicines Counter Assistants (MCAs), dispensing / pharmacy assistants (dispensers) and pharmacy technicians. ${ }^{1}$ Each group performs a number and range of different tasks which sometimes overlap. Broadly, MCAs' respond to requests for non-prescription or over-the-counter (OTC) medicines, as well as advising patients on self-limiting illnesses and healthy lifestyles ${ }^{2,3}$, whereas dispensers and pharmacy technicians support the pharmacist in the assembly of prescribed medicines including the generation of labels and can be involved in providing advice when handing out dispensed medicines. ${ }^{4} \quad$ Whilst overseeing sales of OTC medicines, the pharmacist working alongside dispensers and technicians is often involved in different steps of the dispensing process. ${ }^{5,6}$ This process typically follows a sequential step-wise pattern involving reading and entering the prescription details into a computer, generating labels, selecting and assembling the medicine and attaching labels onto the medicine products. ${ }^{7}$ Legal checks, including a clinical and an accuracy check of the final prescription items are made by the pharmacist before finally bagging the prescription ready to hand to the patient. ${ }^{8}$ Several reports suggest that over the last decade there has been few changes to the pharmacists' work pattern with almost half of their time spent on performing these professional activities of checking prescription appropriateness and accuracy of the final product. Nearly one-third of their time involves assembling and labelling prescription products. ${ }^{9,10}$ Pharmacists' integral involvement in the dispensing process raises questions as to how they are managing to accommodate the delivery of extended pharmacy services and the effect of such services on the workflow of other staff.
The focus of this paper is to explore the perceived impact and consequences on pharmacy supportstaff of the community pharmacy medicines management service 'Medicines Use Reviews' (MURs). In the UK and internationally, policy makers and pharmacy's representative bodies are seeking to promote, formalise and commission patient-centred and advisory services to optimise the use of patients' medicines. ${ }^{11-15}$ MURs have been funded by the UK NHS since 2005. They involve a patient-pharmacist consultation to discuss the patient's use of prescribed and OTC medicines and improve their knowledge about their purpose. One of the requirements of the MUR service is that the consultation be conducted within a consultation area that allows the patient privacy to discuss their medicines and health. ${ }^{16}$ Reports suggest that MUR consultations vary in the time they take to complete depending upon the number of medicines, complexity of the regimen and levels of comprehension of the patient. A national evaluation of the service suggests that an MUR takes an average of 51 minutes in which 22 minutes is spent with the patient and the rest on preparation for the MUR and completing associated paperwork. ${ }^{17}$ Guidance has been issued by the Royal Pharmaceutical Society about the management of pharmacy services when the pharmacist is absent while performing an MUR. ${ }^{18}$ This has allowed services to be continued provided a 'robust' standard operating procedures is in place. However, a deeper understanding of the impact and potential disruption of the pharmacist's absence upon pharmacy staff workflow is needed if new services are to be implemented successfully.

\section{METHODS}

\section{Settings and participants}

Following approval from the East Midlands (Nottingham 2) Research Ethics Committee, two English community pharmacies were recruited purposefully via personal contacts. In order to learn about the different contexts in which MURs were being performed, one pharmacy was a branch of a large multiple (part of a chain retailer) and the other an independent (defined in the UK as a contractor owning five or fewer pharmacies). The multiple pharmacy was located in an affluent town, on a busy high street and was medium-sized compared to other pharmacies that form part of the organisation. The independent pharmacy was situated in a similarly affluent but residential suburb. Inside, the size of the shop floor was smaller than the multiple. The number of prescription items that was dispensed from each pharmacy was approximately the same (1600-1700 items per week).

Consent was obtained from the pharmacists and support-staff for five weeks of ethnographicallyoriented unstructured observations in each pharmacy. AL made detailed field notes between November 2008 and October 2009 of all pharmacy activities, the working environment, staff-patient conversations and all activities relating to MURs. In accordance with the ethnographic approach 


\begin{tabular}{|c|c|c|}
\hline Member of staff & $\begin{array}{c}\text { Independent } \\
(\mathrm{n}=9)\end{array}$ & $\begin{array}{l}\text { Multiple } \\
(\mathrm{n}=8)\end{array}$ \\
\hline Proprietor \& pharmacist & 1 & 0 \\
\hline Manager \& pharmacist & 1 & 0 \\
\hline Employee pharmacist & 0 & 2 \\
\hline Locum pharmacist & 1 & 0 \\
\hline Non-pharmacist manager ${ }^{1}$ & 0 & 1 \\
\hline Dispensing assistant & 3 & 2 \\
\hline $\begin{array}{l}\text { Medicines counter assistant } \\
\text { (MCA) }\end{array}$ & 1 & 2 \\
\hline $\begin{array}{l}\text { Pre-registration (Trainee) } \\
\text { pharmacist }^{2}\end{array}$ & 0 & 1 \\
\hline Saturday staff ${ }^{3}$ & 2 & 0 \\
\hline \multicolumn{3}{|c|}{$\begin{array}{l}{ }^{1} \text { The manager of the multiple was not a pharmacist but was } \\
\text { responsible for meeting the pharmacy's targets, including } \\
\text { those for MURs. } \\
{ }^{2} \text { A pre-registration pharmacist is required to complete a } \\
\text { year of supervised training in employment before } \\
\text { registration as a pharmacist. } \\
{ }^{3} \text { Two undergraduate pharmacy students were employed by } \\
\text { the independent who tended to work on alternate Saturdays } \\
\text { in the dispensary. }\end{array}$} \\
\hline
\end{tabular}

underpinning the study, AL recorded all aspects of the phenomena and the context in which they occurred that seemed relevant to the situation being studied. This enabled detailed observation of behaviour and talk to better understand the social setting in which people function in their natural environment. After the pharmacy observations, five pharmacists and 12 support-staff (Table 1 ) took part in interviews to discuss their perceptions and implementation of the MUR service. Permission was obtained from participants for direct quotes to be used in reports and publications. In this paper pseudonyms have been used to maintain respondents' anonymity.

\section{Data analysis}

Data analysis was inductive, started during the early stages of data collection and was informed by the observations and interviews in order to understand support-staff views and workflow dynamics of the pharmacy. All observation field note documents were typed up, interviews transcribed verbatim and then the data were thematically collated under different headings or 'codes'. ${ }^{19,20}$ The analysis was facilitated using the qualitative software package $\mathrm{N}$ Vivo8. Codes were inductively constructed based upon what was observed and reported in interviews. Transcripts were systematically read through and the contents condensed so that all the different issues that were raised were recorded. Consideration was then given to how these issues might be grouped together in broader themes which were then synthesised and narrated. The principle of constant comparison was used to develop and refine generated themes ${ }^{21}$ which allowed examination of how the MUR was constructed, interpreted and contextualised within the management of the patient's health care. Further details of the interview topic guides and coding framework have been reported elsewhere. ${ }^{22}$

\section{RESULTS}

Patients were seldom observed asking for an MUR and so were identified and invited to the MUR service when they came to the pharmacy to have their prescription filled. Pharmacists, those who worked in the dispensary and MCAs were all involved to some extent in the initial invitation process. However, none of the support-staff (besides the pre-registration (trainee) pharmacist) reported receiving any formal training about the MUR service other than from the pharmacist informing them that it included a brief discussion about the patient's medicines and how they took them. Most understood the potential value of an MUR to patients and framed the service in a positive light but others questioned their purpose and revealed they did not fully understand the point or nature of the service:

Researcher: "...were you informed by the pharmacist about what the purpose of the review is?"

Lucy: "Not really [laughs] no. Only that's it's a financial thing isn't it? But, at the end of the day, I don't know whether, have they got to do it? Is it the law now that this is what they have to do to protect people? Because I don't know really, honestly I don't".

\section{Dispensing assistant, Independent}

In total, 54 MURs consultations were observed (33 from the multiple and 21 from the independent) and workflow noted when the pharmacist returned to the dispensary after performing an MUR. Several concerns were expressed by those working in the dispensary about the disruption to workflow. This proved to be a grievance for some as the pharmacist's absence during MURs was felt to create tension because of patients waiting for their prescriptions:

Helen: "Everything stops; everything stops [laughs] you know. I mean obviously it is a literal stop because we can do all the prescriptions and everything but you're having to say to people 'oh it will be 15 minutes or 20 minutes' ".

\section{Dispenser, Independent}

Dorothy: "I mean, when [names locum pharmacist] was here, that just got ridiculous. Because he went in with an MUR, middle of a Friday morning, and it was literally me left there on my own, and he was gone for ages. And that was just beyond a joke..."

\section{Dispenser, Multiple}

Observations and interviews with dispensing staff revealed that tensions arose when there was a build-up of prescriptions to be checked. This did happen occasionally when the pharmacy was busy and the pharmacist present. However, patients were reported to be more irritated during periods when the pharmacist was not physically visible to patients, such as when engaged with an MUR. Under these 
circumstances patients were considered more likely to take their prescriptions to be filled elsewhere:

Sophie: "...if you tell them to wait for ten to fifteen minutes, they would just say "why do I need to wait for fifteen minutes?"...so, some of them will go to another pharmacy. That's like the worst objection".

\section{Pre-registration pharmacist, Multiple}

Lucy: "I think it's frustrating. Frustrating from the fact that you know people are waiting for prescriptions and you're having to say the pharmacist has got a patient in with her at the moment. People just want to go don't they? They want their prescription, and they're not bothered about why she's interviewing another patient..."

\section{Dispensing assistant, Independent}

Uncertainty over how long the pharmacist would take to return from an MUR hindered the ability to manage patient expectations. To avoid such situations, those working in the dispensary deployed a range of tacit strategies to maintain and manage patient and customer expectations. Support-staff in the multiple were conscious of the effects of the managerial pressure upon the pharmacist to undertake MURs. This pressure within the multiple led to pharmacists reporting selecting patients on fewer medicines or those with less complex medical conditions which could be conducted quickly and efficiently in order to reach the targeted number of MUR. Dispensary staff did not reporting feeling similar pressure or burden to achieve the organisation's MUR target. Rather, they were more concerned about the knock-on effects of the pharmacist's absence. A response reported by one dispenser was to invite for an MUR patients who had fewer medicines that could be 'processed' more quickly resulting in a shorter consultation. This was despite her acknowledging that patients on a larger number of medicines and with more complex medication regimes would potentially derive greater benefit from a review:

Dawn: "This is when it doesn't work because you try to avoid the ones that have got like, fifteen [prescription] items. Because unless you've got two pharmacists, in which case it's no problem whatsoever, but if you've only got one pharmacist and they're on about fifteen, twenty items, you just really can't warrant that time for pharmacists not to be checking walkin prescriptions".

\section{Dispenser, Multiple}

Other strategies included ways of deliberately influencing patient expectations. Initially patients who were waiting for the prescriptions to have an accuracy check were told the pharmacist was busy and provided with an estimated time when their prescription would be ready. Some of these time estimates were extended if a pharmacist was known to take longer to perform the MURs:

Sophie: “...I know like the pattern of the pharmacist doing an MUR. For Kate [pharmacist] I will try to give more time [laughter]".

Pre-registration pharmacist, Multiple

All support-staff were aware that they could interrupt the pharmacist during an MUR. This happened occasionally and involved the assembled prescription items being brought into the consultation room during a consultation for them to be checked. Support-staff made personal judgements about the balance between respecting the privacy of the consultation and the need to appease waiting patients:

Helen: ...you don't like doing that because that's private, you don't like interrupting them but you feel you will because its dragged on so long ...you can't say "well they're not out yet" and then expect them to wait another 10 minutes so you feel obliged to interrupt [the MUR]...I mean if you're in the doctor's surgery you wouldn't want the receptionist knocking on the door would you while you were having a consultation.

\section{Dispenser, Independent}

In contrast to dispensing staff, whose work was seen to be directly dependent upon the pharmacist being present, those working on the medicines counter were observed to have less obstruction to workflow. One MCA reported her customers on the whole to be tolerant. The pharmacist's absence was not felt to be an issue since they were usually available again after a short while:

Stef: "...Most of the customers are patient and they will wait or they'll sort of go away and come back later. I've never had anybody that's been, you know, annoyed that there's no pharmacist available. No".

MCA, Multiple

Nevertheless, concerns were expressed by MCA who reported feeling helpless and awkward when customers were waiting to speak to the pharmacist or when waiting to collect their prescriptions. This was at times very uncomfortable and had personal consequences:

Cath "...I do feel like sometimes, I don't know, like a duck at a fairground you know, like the hook a duck sort of thing or rifle range. 'Cause people are sitting there waiting to see the pharmacist or are waiting for the prescription and I'm on the shop floor and they're looking at me as if to say "why can't you do it"...I walk up and down, I feel they're following me everywhere. Well I can't do anything! It's not me! It's the pharmacist! You know, I do feel that like I get daggers pointed at me, ohh".

\section{MCA, Independent}

Another point made was that pharmacy's professional representatives have in the past gone to considerable efforts to demonstrate the community pharmacist's availability to customers without appointment. This seemed contradictory to one MCA in situations where she would have to 
inform customers that the pharmacist was unavailable:

Leah: "...you see, on the television, they often run 'Ask your pharmacist' campaigns, so people will come in to speak specifically to the pharmacist and of course [during an MUR], they're not available".

\section{MCA, Multiple}

When asked about how the MUR service could be improved, it was suggested that an additional pharmacist or an accredited pharmacy checking technician who could perform prescription accuracy checks would help resolve the problem. However, it was acknowledged that the organisation's budgetary constraints would not make having additional staff to support MUR activity financially viable:

Kay: "I do think that if you're having the pharmacist who's doing MURs you should have somebody there to back up....because it is infuriating waiting for things".

\section{Dispenser, Independent}

Stef: "They won't give us two pharmacists every day will they [in order to perform MURs]...so long as one is available..."

\section{MCA, Multiple}

Observations revealed that MURs were pragmatically accommodated alongside existing duties without additional resource. As a result work flow was impeded during this period. Problems with work piling up were more noticeable when only one pharmacist was on duty and they felt pressure to return to their 'traditional' shop floor duties. Pharmacists recognised the pressure their absence placed on support staff:

Rebecca: ... I think they [support staff] feel under pressure because we're so used to having such a very good system and people don't have to wait long...so for that period of time they do feel under pressure, that oh my God, like, people have got a waiting time and things are piling up...

\section{Manager \& pharmacist, Independent}

Pharmacists were seen undertaking MURs when convenient to the workload of the pharmacy with patient recruitment and MUR consultations being abandoned when the pharmacy was very busy. Pharmacists, particularly those working for the multiple, reported feeling pressurised to deliver a targeted number of MURs. The expectations of support staff as well as the patients / customers were at the back of the pharmacist's mind when performing an MUR. One employee pharmacist reported being placed in a difficult position where she had, on one hand, corporate pressure to achieve a targeted number of MURs, while on the other, the pressure resulting from her awareness of the added stress her absence from the dispensing area caused support staff:
Jane: "...I try and be sympathetic to the staff and say "look, I'm really sorry, but I've really got to do this one". Because you've got the target, you've got to achieve your target and I daren't say no to an MUR... I hope it's not obvious to the person in the MUR room that you're trying to rush through because you're conscious of the impact it's having on the rest of the business".

Employee pharmacist, Multiple

\section{DISCUSSION}

Pharmacists' views and the barriers they face when adopting extended roles alongside existing duties have been well documented. ${ }^{23-27}$ However, the views of pharmacy support-staff and the consequences of the pharmacist being away from the dispensary while engaged in activities such as MURs have largely been neglected. This study provides insights into the views of support staff and the importance of the pharmacist being present in the dispensing area to undertake a professional check on each prescription processed along with a final accuracy review of the dispensed medicines. There were few indications of any clear formal operating procedures implemented to manage and maintain workflow during periods when the pharmacist is conducting an MUR. Rather, dispensing staff were largely expected to handle patient and customer expectations as best they could sometimes with the use of strategies to avoid grievances. Others have reported that owners have struggled to conduct MURs whilst maintaining dispensing volumes and that the pharmacist's absence during an MUR has negatively impacted on patient satisfaction when patients are asked to wait for their prescriptions. ${ }^{17,28,29}$ With dispensing work heavily reliant on the pharmacist providing professional and accuracy checks, policy makers and those wishing to promote extended patientconsultative services should acknowledge the consequences on existing services and thus for support-staff waiting with patients for the pharmacist to return to 'traditional' duties.

This study highlights several implications for pharmacy organisations. A critical review of the pharmacy's standard operating procedures may be warranted to ensure that when the pharmacist is engaged in a MUR sales of OTC and dispensing services can be feasibly maintained. Additionally, there is a need to ensure that the service is targeting the patients who may benefit most and not those whose MUR are perceived to take less time. As has been reported in other studies, pharmacists particularly in the multiple, were acutely aware of the corporate drive to deliver a targeted number of MURs and reported feeling pressurised to undertake MUR activity to achieve the maximum quota. ${ }^{28-32}$ Pharmacists in this study were aware of the consequences of lengthy periods away from the dispensary. Others have also reported that MURs have been incorporated into the daily work of the pharmacy without additional pharmacist cover. ${ }^{17,30}$ If having two pharmacists on duty is not financially viable, more creative solutions may be required to 
ensure prescription output is maintained. A detailed review of the workflow, team structures, pace of work and investment in pharmacy technicians, who can be trained to undertake accuracy checks on dispensed medicines (Accuracy Checking Technician), could contribute to managing services when the pharmacist is engaged in MURs. Likewise, employing part time locums to help with MUR clinics during specified times during the week could be another solution. Current support-staff roles appear to be well embedded and defined ${ }^{33}$ and others have suggested that decisions about how dispensary support staff are utilised are more appropriately made at an individual community pharmacy level. ${ }^{2}$ It is clear, however, that a culture of developing a pre-planned and orderly system of working where the pharmacists are not hurried and support-staff are not left without adequate support is needed to ensure there is successful innovation and policy implementation of this extended role.

\section{Strength and limitations of the study}

To our knowledge this is the only observational study that has sought to explore support-staff views of MURs and its implementation as it is experienced naturalistically on the ground as a situated healthcare intervention. This study used a combination of two qualitative research methodological approaches to enhance the credibility of the findings. The triangulation of direct observation (researcher's accounts) with accounts provided by respondents in interviews provided a powerful means of understanding the complexity of respondents' views, how these may shift contextually and the situational pressures which underlie them. The time spent in the pharmacies allowed rapport and trust to be built between the researcher and support-staff and enabled a deeper understanding of how micro-factors impinged on workflow and delivery of MUR. However, this case study was conducted in two discrete geographical locations. It is unknown to what extent the findings from the two study sites are transferable to other pharmacies which have different levels of supporting staff or pharmacists who may perceive the MUR service and its implementation differently.
Furthermore, a well known limitation to fieldwork observations is the unknown effect of the researcher's presence on participants. The longitudinal nature of the study was intended to reduce the extent to which participants modify behaviour as a result of a heightened awareness of the observer. Future research agendas should focus on the patient experience of MURs which is needed in a wider and more diverse range of community pharmacy settings.

\section{CONCLUSIONS}

MURs provide a nationally recognised extended counselling role for UK community pharmacists. The study findings highlight the need for policy makers and professional bodies to consider pharmacists' existing responsibilities and strong commitment to the dispensing process and how new roles affect existing service provision and impact on the work of other pharmacy staff. Requirements for pharmacists to adjust their work focus will continue over the coming years as they increasingly take on extended roles. Workflow management and increased resource are needed if pharmacy staff are to avoid improvisations or enactments and have an ordered linear path to a pre-defined work pattern that accommodates all parties.

\section{ACKNOWLEDGEMENTS}

The authors would like to thank the patients, pharmacists and pharmacy staff who took part in this study.

\section{CONFLICT OF INTEREST}

The authors do not have any competing interests.

Funding: AL'S PhD. was funded by the Economic and Social Research Council (ESRC) and Medical Research Council (MRC). The ideas expressed in this manuscript are those of the authors and in no way are intended to represent the position of the funding council.

\section{References}

1. Royal Pharmaceutical Society of Great Britain. Pharmacy support staff roles and definitions (updated May, 2009); 2009. http://www.docstoc.com/docs/27981460/Pharmacy-support-staff-roles-and-definitions (Accessed 13 Mar 2013).

2. Ylänne $V$, John DN. Roles of medicines counter assistants in advice giving in community pharmacies: a Discourse Analysis. Pharm World Sci. 2008;30(2):199-207.

3. Banks J, Shaw A, Weiss MC. The community pharmacy and discursive complexity: a qualitative study of interaction between counter assistants and customers. Health Soc Care Community. 2007;15(4):313-321.

4. Mullen R. Skill mix in community pharmacy: exploring and defining the roles of dispensary support staff. London: Royal Pharmaceutical Society of Great Britain; 2004.

5. Lea VM, Corlett SA, Rodgers RM. Workload and its impact on community pharmacists' job satisfaction and stress: a review of the literature. Int J Pharm Pract. 2012;20(4):259-271. doi: 10.1111/j.2042-7174.2012.00192.x.

6. Rutter PM. Pharmacist work patterns: are they affected by staffing levels and prescription numbers? Int J Pharm Pract. 2002;10(suppl):R49.

7. Savage I. Time for customer contact in pharmacies with and without a dispensing technician. Int J Pharm Prac. 1995;3(4):193-199

8. Royal Pharmaceutical Society. Medicines, Ethics and Practice: The professional guide for pharmacists. Edition 36. London: Royal Pharmaceutical Society; 2012. 
9. Bell HM, McElnay JC, Hughes CM. A self-reported work sampling study in community pharmacy practice. Pharm World Sci. 1999;21(5):210-216.

10. McCann L, Hughes CM, Adair CG. A self-reported work-sampling study in community pharmacy practice: a 2009 update. Pharm World Sci. 2010;32(4):536-543. doi: 10.1007/s11096-010-9405-x.

11. Edmund J, Calnan MW. The reprofessionalisation of community pharmacy? An exploration of attitudes to extended roles for community pharmacists amongst pharmacists and General Practitioners in the United Kingdom. Soc Sci Med. 2001;53(7):943-955

12. Noyce, PR. Providing patient care through community pharmacies in the UK: Policy, practice, and research. Ann Pharmacother. 2007;41(5):861-868.

13. Commonwealth Department of Health and Aged Care. Domiciliary Medication Management-Home Medicines Review. Helping your patients manage their medicines at home. Canberra: Commonwealth Department of Health and Aged Care, 2001. http://pivotwest.org.au.titan.imagin8.com/icms_docs/12623_What_is_DMMR_.pdf (Accessed 13 Mar 2013).

14. Dolovich L, Gugnon A, McAiney CA, Sparrow L, Burns S. Initial pharmacist experience with the Ontario-based MedsCheck program. Can Pharm J. 2008;141(6):339-345. doi: 10.3821/1913-701X-141.6.339

15. Lee E, Braund R, Tordoff J. Examining the first year of Medicines Use Review services provided by pharmacists in New Zealand: 2008. N Z Med J. 2009;122(1293):3566.

16. Department of Health. The Pharmaceutical Services (Advanced and Enhanced Services) (England) Directions. London: Department of Health; 2005.

17. Blenkinsopp A, Bond C, Celino G, Inch J, Gray N. National Evaluation of the New Community Pharmacy Contract. London: Pharmacy Practice Research Trust, 2007.

http://www.pprt.org/Documents/ResearchFunding/National_evaluation_of_the_new_community_pharamcy_contract.pdf (Accessed 17 Mar 2013).

18. Royal Pharmaceutical Society of Great Britain (2005) Law and Ethics Bulletin. Interim Guidance for pharmacist supervision and private consultation areas. http://faculty.ksu.edu.sa/hisham/Documents/RPSGB_Files_/7/LEBphsupconsultareas.pdf (Accessed 13 Mar 2013).

19. Silverman D. Interpreting Qualitative Data - methods for analysing talk, text and interaction. Thousand Oaks: CA: Sage Publication; 1993.

20. Ziebland S, McPherson A. Making sense of qualitative data analysis: an introduction with illustrations from DIPEx (personal experiences of health and illness). Med Educ. 2006;40(5):405-414.

21. Charmaz K. Constructing grounded theory. A practical guide through qualitative analysis. Thousands Oaks: Sage; 2006.

22. Latif A, Pollock K, Boardman H. The contribution of the Medicines Use Review (MUR) consultation to counseling practice in community pharmacies. Patient Educ Couns. 2011;83(3):336-344. doi: 10.1016/j.pec.2011.05.007.

23. Bradley F, Elvey R, Ashcroft DM, Hassell K, Kendall J, Sibbald B, Noyce P. The challenge of integrating community pharmacists into the primary health care team: A case study of local pharmaceutical services (LPS) pilots and interprofessional collaboration. J Interprof Care. 2008;22(4):387-398. doi: 10.1080/13561820802137005.

24. Eades EC, Ferguson JS, O'Carroll RE. Public health in community pharmacy: A systematic review of pharmacist and consumer views. BMC Public Health. 2011;11:582. doi: 10.1186/1471-2458-11-582.

25. Lounsbery JL, Green CG, Bennett MS, Pedersen CA.Evaluation of pharmacists' barriers to the implementation of medication therapy management services. J Am Pharm Assoc (2003). 2009;49(1):51-58. doi: 10.1331/JAPhA.2009.017158.

26. Niquille A, Lattmann C, Bugnon O. Medication reviews led by community pharmacists in Switzerland: a qualitative survey to evaluate barriers and facilitators. Pharm Pract. 2010;8(1):35-42.

27. Roberts AS, Benrimoj SI, Chen TF, Williams K, Aslani P. Implementing cognitive services in community pharmacy: a review of facilitators used in practice change. Int J Pharm Prac. 2006:14(3):163-170.

28. McDonald R, Cheraghi-Sohi S. Sanders, C, Ashcroft D. Professional status in a changing world: The case of Medicines Use Reviews in English community pharmacy. Soc Sci Med. 2010;71(3):451-458. doi: 10.1016/j.socscimed.2010.04.021.

29. Urban R, Rivers $P$, Morgan J. Perceptions of medicines use reviews - the views of community pharmacists within a West Yorkshire primary care trust. Pharm J. 2008;281(7519):303-305.

30. Bradley F, Wagner AC, Elvey R, Noyce PR, Ashcroft DM. Determinants of the uptake of medicines use reviews (MURs) by community pharmacies in England: A multi-method study. Health Policy. 2008;88(2-3):258-268. doi: 10.1016/j.healthpol.2008.03.013.

31. Harding G, Wilcock M. Community pharmacists' perceptions of medicines use reviews and quality assurance by peer review. Pharm World Sci. 2010;32(3):381-385. doi: 10.1007/s11096-010-9381-1.

32. Wilcock M, Harding G. What do pharmacists think of MURs and do they change prescribed medication? Pharm J. 2008;281(7514):163-167.

33. Braund R, Chesney KM, Keast EP, Ng LJ, Qi S, Samaranayaka S, Wang E. Are all pharmacy staff interested in potential future roles? Int J Pharm Pract. 2012;20(6):417-421. doi: 10.1111/j.2042-7174.2012.00216.x. 